\title{
A study on power-controlled wire-arc additive manufacturing using a data-driven surrogate model
}

\author{
Rameez Israr ${ }^{1} \cdot$ Johannes Buhl ${ }^{1} \cdot$ Markus Bambach $^{2}$ \\ Received: 27 January 2021 / Accepted: 26 May 2021 / Published online: 22 June 2021 \\ (C) The Author(s) 2021
}

\begin{abstract}
Wire-arc additive manufacturing (WAAM) provides an alternative for the production of various metal products needed in medium to large batch sizes due to its high deposition rates. However, the cyclic heat input in WAAM may cause local overheating. To avoid adverse effects on the performance of the part, interlayer dwelling and active cooling are used, but these measures increase the process time. Alternatively, the temperature during the WAAM process could be controlled by optimizing the welding power. The present work aims at introducing and implementing a novel temperature management approach by adjusting the weld-bead cross-section along with the welding power to reduce the heat accumulation in the WAAM process. The temperature evolution during welding of weld beads of different cross-sections is investigated and a database of the relation between optimal welding power for beads of various sizes and different pre-heating temperatures was established. The numerical results are validated experimentally with a block-shaped geometry. The results show that by the proposed method, the test shape made was welded with lower energy consumption and process time as compared to conventional constant-power WAAM. The proposed approach efficiently manages the thermal input and reduces the need for pausing the process. Hence, the defects related to heat accumulation might be reduced, and the process efficiency increased.
\end{abstract}

Keywords Wire-arc additive manufacturing $\cdot$ Numerical analysis $\cdot$ Experimental investigation $\cdot$ Welding parameters $\cdot$ Welding power $\cdot$ Weld-bead size $\cdot$ Heat accumulation $\cdot$ Pause time

\section{Introduction}

Additive manufacturing (AM) processes are flexible manufacturing processes suitable for unit as well as small batch production [1]. In the field of AM, wire-arc additive manufacturing (WAAM) is categorized as a directed energy deposition (DED) process in which a heat source melts a metal wire and deposits it by a computercontrolled motion layer by layer on the substrate [2, 3]. The heat source in WAAM is mostly an electrical arc with a consumable electrode, i.e., a gas metal arc welding

Rameez Israr

Rameez.Israr@b-tu.de

1 Chair of Mechanical Design and Manufacturing, Brandenburg University of Technology, Cottbus, Senftenberg,

Konrad-Wachsmann-Allee 17, D-03046 Cottbus, Germany

2 Advanced Manufacturing Lab, ETH Zurich, Leonhardstrasse 27, 8092 Zurich, Switzerland process (DED-GMAW). The process is capable of producing complex 3D components $[4,5]$.

In comparison to powder-bed fusion AM processes, the cost and manufacturing time of larger components built through WAAM is lower as the deposition rate is much higher, i.e., of the order $2-4 \mathrm{~kg} / \mathrm{h}$ [6]. Recently, WAAM method has been successfully applied to manufacture various largescale parts and structures, i.e., marine propeller-bracket [7], stainless-steel diagrid column [8], landing gear rib [9], and a $12.5 \mathrm{~m}$ long metal footbridge [10]. Ding et al. [4] confirmed that the limitations of the other AM processes are increasing the demand for the WAAM process. However, the repeated heat input can produce high local temperatures in the work piece, so that a pause time is required before the welding process can be continued. Local overheating leads to various defects like 'running' of the deposited molten material, thermal distortion, residual stresses, and even the formation of cracks [11-13]. Yang et al. [14] described that with the increase in the welding layers, i.e., part height, the heat accumulation becomes more significant. According to $\mathrm{Wu}$ et al. [15], the heat accumulation with increasing layers is due to the 
reduced conduction to the substrate. As the build height increases, convection and radiation become the dominant heat transfer mechanism, which is insufficient as compared to the conduction into an actively cooled substrate.

The heat accumulation not only influences the geometry of the components but also affects its mechanical properties, microstructure, and grain size. Xiong et al. [16] showed that the heat accumulation during WAAM of low carbon steel resulted in a geometric deviation and irregularities in the molten pool. Wu et al. [17] reported heat accumulation as the main cause of wall width enlargement and excessive oxidation of the prewelded beads during WAAM of a titanium alloy. Manwatkar et al. [18] also verified that with the increasing height of a wall built by WAAM, the heat accumulation increases while the cooling rate and hardness decrease. According to Hoshi et al. [19], the accumulation of heat is associated with the material's heat capacity. For example, due to higher heat capacity, the heat accumulation in titanium is more than in steel. Li et al. [20] stated that heat accumulation causes microstructure inhomogeneity and results in large grain sizes in areas with high temperature. Chen et al. [21] indicated that high temperature during welding cause the final microstructure to coarsen and the mechanical properties to deteriorate. According to Pandey et al. [22], high temperature gradients and heat accumulation during welding are responsible for the inhomogeneous development of the microstructure and also cause the variations in the mechanical properties of the final parts. Wu et al. [23] illustrated that heat accumulation causes changes in geometrical shape of the build WAAM part. Furthermore, the microstructure and grain size are affected by the thermal history of the WAAM process. Heat accumulation in specific regions causes slower cooling, resulting in larger grain size and inhomogeneity in microstructure and mechanical properties [23]. Therefore, for improving the quality of metal components produced by WAAM, the heat accumulation should be managed efficiently.

In the past, different approaches have been proposed to optimize the thermal history and to avoid the adverse effects of heat accumulation during the WAAM processes. Rajamanickam et al. [24] proposed that welding velocity and tool rotation are the influencing parameters for controlling the temperature during welding and should be carefully managed for multilayer arc welding. Similarly, Eagar and Tsai [25] observed variations in the maximum temperature of the layers during welding. They reported that the welding power, welding traveling speed of the torch, and thermal diffusivity have a significant role in determining the temperature history, and the weld bead profile. These technological parameters should be properly adjusted to control the welding temperature of each layer.

During the last few decades, numerical simulation methods have been developed for predicting the thermal behavior, residual stresses, and distortions in welding [26-29].
Kozamernik et al. [30] stated that heat accumulation in the multi-layer WAAM process leads to high thermal stresses. They controlled the unwanted temperature development between the layers by using two different approaches, i.e., by introducing a delay time between the layers and by applying compressed airflow to the top layer during welding. Derekar et al. [31] reported that the continuous welding of beads in layers results in a progressive increase in temperature and thermal stresses. They implemented a dwell time between the beads to control the temperature in each of the beads. Silva et al. [32] showed that the physical properties of the specimen are affected by the heat accumulation during the WAAM process due to different temperatures in each layer. They found that regulating the operating temperature by introducing idle time helps to minimize heat accumulation. Hu et al. [33] developed a three-dimensional WAAM simulation model for the remanufacturing of hot forging dies. They suggested that the temperature of the layers could be controlled by adjusting the input power during welding.

The state of the art presented above reveals that one of the most critical issues that have to be addressed in the WAAM process is heat accumulation. Each of the abovementioned methods has its advantages and shortcomings; hence, the goal is to develop a method for controlling heat accumulation irrespective of the geometry of the specimen and without compromising the productivity. An estimate of the required input welding power as a function of pre-heating temperature and the bead size is needed to reduce heat accumulation as much as possible. This requires welding with beads of different cross-section.

This paper addresses the abovementioned issues and is organized as follows: In section 2, the material and methods are introduced. A one-bead model is used to establish the database and a block-shaped geometry is used to validate the database. In section 3, a detailed comparison of the constant power welding strategy and the proposed power-controlled welding is presented followed by the experimental validation of the numerical results. Finally, in section 4, the conclusions are drawn based on the presented results.

\section{Materials and methods}

In this section, the experiments are performed to measure the heat accumulation in specimens produced by conventional and power-controlled WAAM approaches. Whereas to validate the experimental results, the finite element analysis are performed with the same geometries and input parameters.

\subsection{Experimental work}

In this research, a robot-based WAAM system has been used as shown in Fig. 1. The welding torch was installed on a six- 
Fig. 1 Robot-based WAAM system using CMT technology

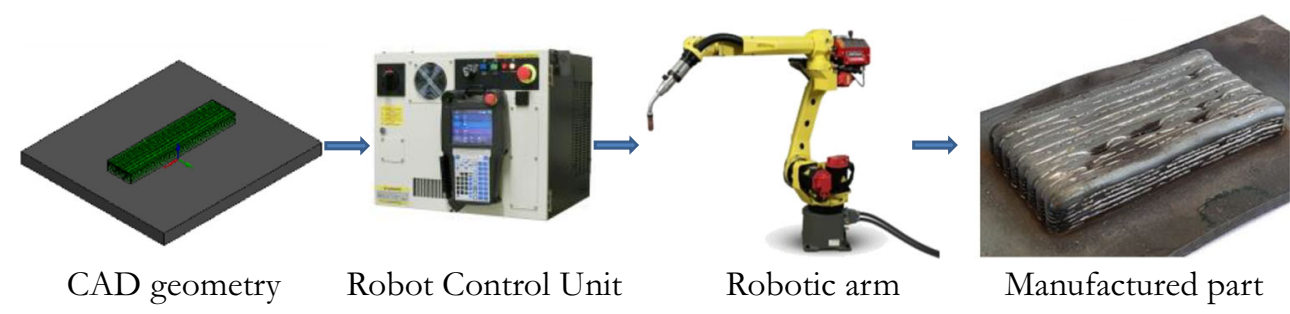

axis FANUC welding robot. The welding paths were generated using the software Rhino 3D for slicing and Matlab for converting the output of the slicing process into the robot programming language. The job files generated this way were imported into the robot control system. A Fronius TPS500i power source was used for GMAW welding. The cold metal transfer (CMT) welding mode was used. A steel electrode wire (ER70S-6) with a diameter of $1.0 \mathrm{~mm}$ was used for the WAAM process. To protect the molten deposited material from oxidation, a mixture of argon and $\mathrm{CO}_{2}$ in the ratio of $80: 20$ with a flow rate of $15.0 \mathrm{~L} / \mathrm{min}$ was applied as shielding gas. The temperature distributions throughout the welding process were recorded using an infrared camera by InfraTec $\mathrm{GmbH}$, Germany, using a constant emission coefficient of 0.9 throughout the welding process.

A rectangular plate $\left(121.5 \times 110 \times 4 \mathrm{~mm}^{3}\right)$ was mounted on the welding table and used as substrate.

\subsection{Welding of test geometries}

\subsubsection{Conventional WAAM}

A rectangular block (length: $81 \mathrm{~mm}$; width: $18 \mathrm{~mm}$ ) was manufactured using constant power WAAM, i.e., by progressive welding of weld beads with constant cross-section and power (Fig. 5). Five layers were defined to weld the block. The width and height of the beads in each layer correspond to $4.5 \mathrm{~mm}$ and $1.337 \mathrm{~mm}$ reaching a total height of about 6.7 $\mathrm{mm}$. The beads were welded in such a way that the welding direction of one layer was opposite to the next layer. To account for the relocation of the welding torch, a delay/cooling time of $2 \mathrm{~s}$ was set before welding the next layer.

\subsubsection{Power-controlled approach}

In the power-adjusted welding process, the same block geometry was welded with variable layer height, as the crosssections of the weld beads changed in each layer of the block as a function of travel speed and input power. To reach the same height as in the constant power welding process, a fivelayer block with varying cross-sections of the weld beads was set up to elaborate and validate the concept of adjusting welding power over the layers. The values of bead width and height to model the block were determined using the equations (1) and (2), which were already developed in previous work [25] and extended using new experimental data.

$v_{a d}=687.34 h^{-1.987}$

$w_{\text {ad }}=-0.7359 h^{2}+5.2982 h-1.2773$

Figure 2 shows the comparison of the available [34] and adapted interpolation functions between the heat source travel speed - weld bead height and the weld bead width-weld bead height.

Here, $v(h)$ and $w(h)$ are obtained from the interpolation curves that are reported by Lam et al. [34], while the velocity and width fitting curves are expressed as $\mathrm{v}_{\mathrm{ad}}$ and $\mathrm{w}_{\mathrm{ad}}$. The adapted bead dimensions for the block agreed with the reported value, which is also verified by the overlapping curves in the graph. The values used for the five-layered block are shown in Table 1. These values are used in the experiments and numerical simulations. As a result of the simulations, a database was set up that allows for choosing an appropriate welding power depending on bead geometry and pre-heating temperature. This database was used to adapt the welding power in the experiments. The simulation approach and setting up of the database are explained in the subsequent section.

\subsection{FE simulation and database generation}

\subsubsection{Heat source model}

Heat source modeling was accomplished using Goldak's double ellipsoidal heat source [35]. The distribution of the heat in the front of the heat source is given by Eq. (3).

$q_{f}(x, y, z, t)=\frac{6 \sqrt{3} f_{f} Q}{\pi \sqrt{\pi} w d c_{f}} e^{-3\left(\frac{x}{w}\right)^{2}} e^{-3\left(\frac{y}{d}\right)^{2}} e^{-3\left(\frac{z+v(\tau-t)}{c_{f}}\right)^{2}}$

For the rear volume, the heat source is defined using Eq. (4).

$q_{r}(x, y, z, t)=\frac{6 \sqrt{3} f_{r} Q}{\pi \sqrt{\pi} w d c_{r}} e^{-3\left(\frac{x}{w}\right)^{2}} e^{-3\left(\frac{y}{d}\right)^{2}} e^{-3\left(\frac{z+v(\tau-t)}{c_{r}}\right)^{2}}$

Here, $q_{f}$ and $q_{r}$ represent the energy distribution in the front and rear area of the heat source and $x, y, z$ are the local coordinate systems that are aligned with the line of material 
Fig. 2 Comparison of the available [34] and adapted (for block) scatter chart and interpolation function between heat source travel speed-bead height and between bead widthbead height
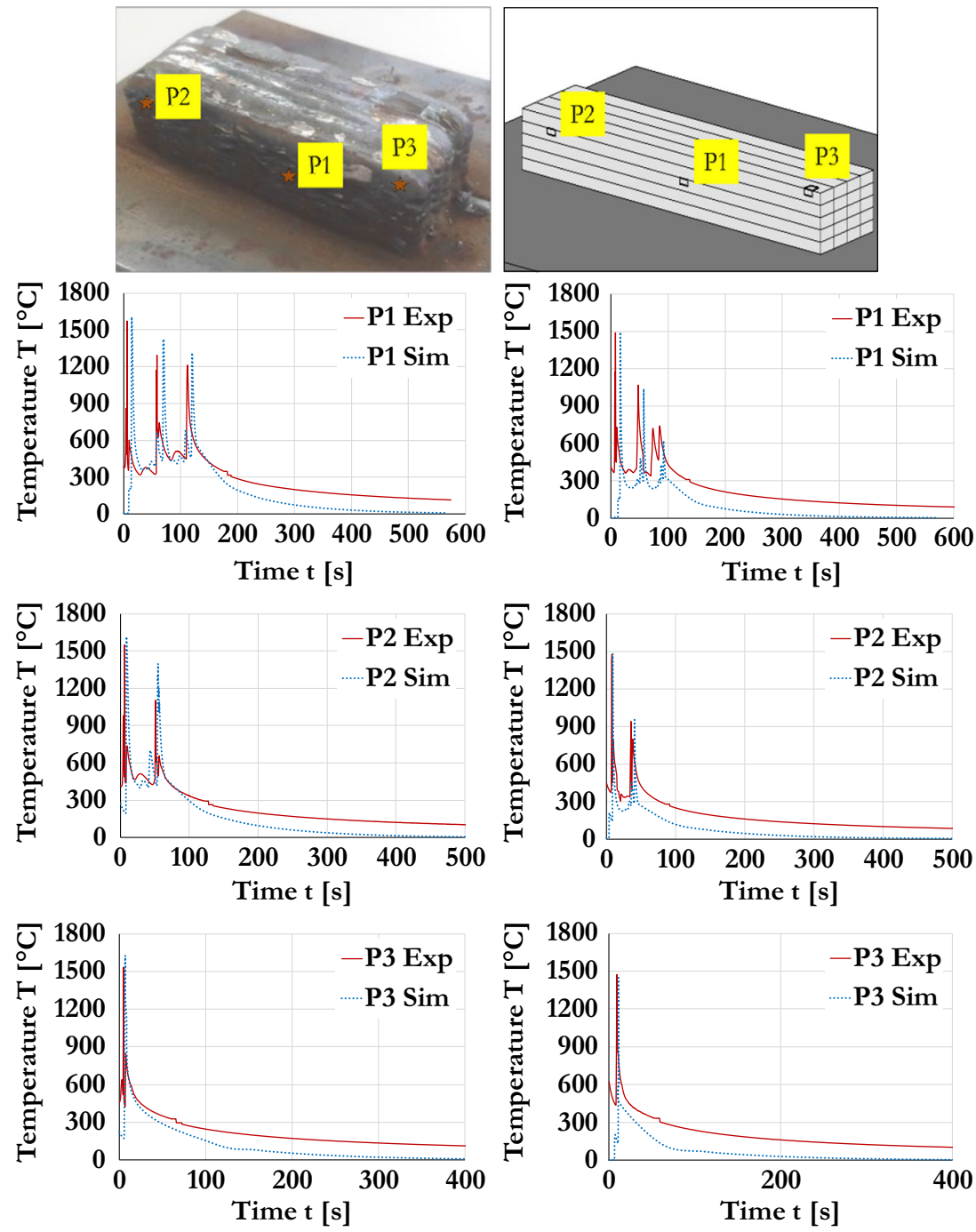

Conventional approach

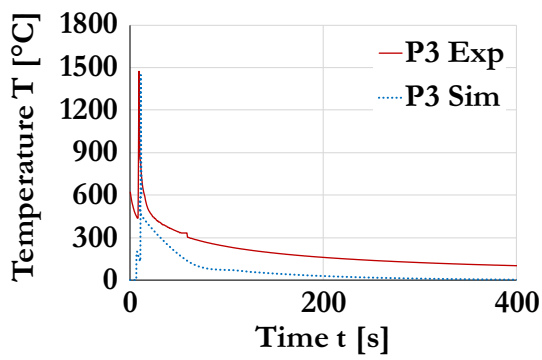

Proposed approach deposition. The weld pool energy $\boldsymbol{Q}$ can be calculated using the following equation:

$$
Q=\mu V I
$$

Here, $\boldsymbol{\mu}$ is the efficiency of the heat source and is taken as 1, while $\boldsymbol{V}$ and $\boldsymbol{I}$ are voltage and current of the heat source. The

Table 1 Adapted velocity, weld bead widths, and heights in each layer

\begin{tabular}{llll}
\hline Layer no. & $\begin{array}{l}\text { Weld bead width } \\
{[\mathrm{mm}]}\end{array}$ & Weld bead height $[\mathrm{mm}]$ & $\begin{array}{l}\text { Velocity } \\
{[\mathrm{mm} / \mathrm{s}]}\end{array}$ \\
\hline 1 & 6.00 & 1.85 & 4.5 \\
2 & 4.50 & 1.33 & 6.4 \\
3 & 3.60 & 1.09 & 9.6 \\
4 & 3.00 & 0.935 & 13.0 \\
5 & 2.57 & 0.812 & 17.6 \\
\hline
\end{tabular}

parameters of the Goldak's heat source that have been used in this work are adapted from the literature review of Israr et al. [36] and Prasad et al. [37] and are detailed in Table 2. The

Table 2 Goldak's heat source parameters

\begin{tabular}{lll}
\hline Parameter & Symbol & Value \\
\hline Weld pool width & $\mathrm{w}$ & $\frac{1}{2}$ (Width of bead) \\
Weld pool depth & $\mathrm{d}$ & $\begin{array}{l}\text { Depth of bead }+0.1 \\
\text { Weld pool }\end{array}$ \\
$\begin{array}{l}\text { (forward direction) } \\
\text { Weld pool }\end{array}$ & $\mathrm{c}_{\mathrm{f}}$ & 2.0 \\
(rear direction) & $\mathrm{f}_{\mathrm{r}}$ & 8.0 \\
Forward heat factor & $\mathrm{f}_{\mathrm{r}}$ & 0.6 \\
Rearward heat factor & $\mathrm{n}$ & 1.4 \\
Exponent constant & 1.0 \\
\hline
\end{tabular}


Fig. 3 Illustration of the numerical model for establishing a database to determine the influence of the welding power on the heat input

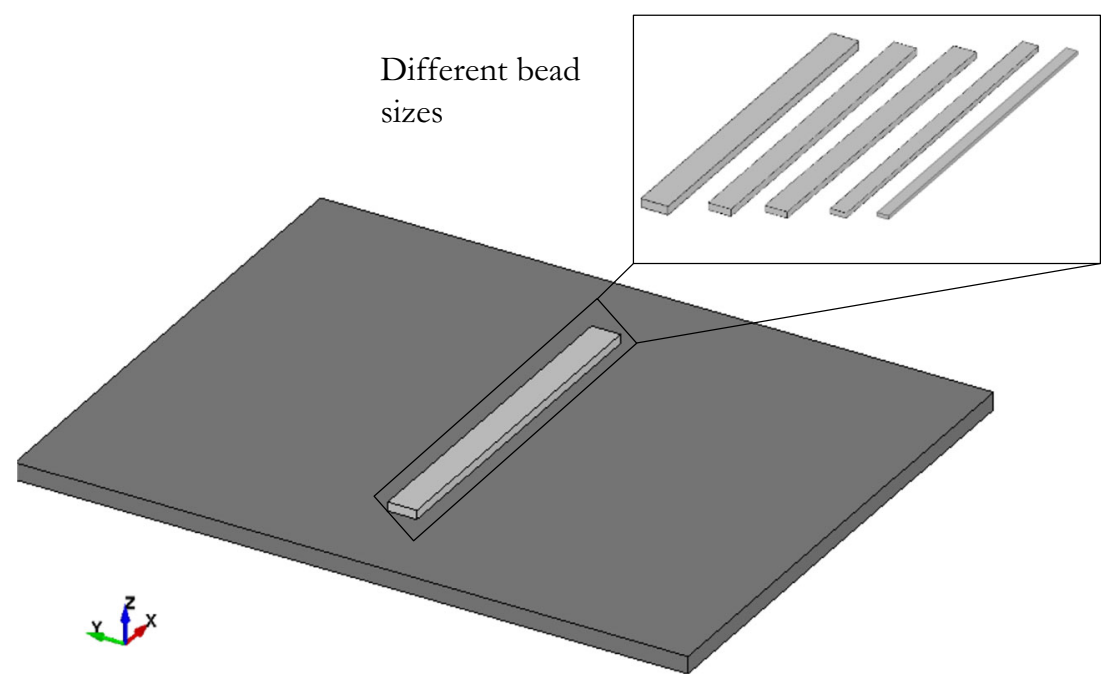

\subsubsection{One bead model for establishing the database}

and width are obtained from equations (1) and (2).

\subsubsection{Material model}

For material modeling, the existing thermal material definition from the LS-DYNA material library was used. All FE analyses were carried out with the *MAT_Thermal_CWM T07 model. The weld beads were modeled using the material properties of steel grade 309L [36], while the substrate was modeled with properties for structural steel S235 [38-40]. To model the material deposition on the substrate, the quiet element technique was implemented in this work. In this technique, the elements of all beads were defined as quiet/inactive at first and were later activated layer by layer by the moving heat source.

Table 3 Welding velocities and corresponding bead height and width [34]

\begin{tabular}{lll}
\hline $\begin{array}{l}\text { Welding } \\
\text { velocity v } \\
(\mathrm{mm} / \mathrm{s})\end{array}$ & $\begin{array}{l}\text { Corresponding } \\
\text { Height H } \\
(\mathrm{mm})\end{array}$ & $\begin{array}{l}\text { Corresponding } \\
\text { Width W } \\
(\mathrm{mm})\end{array}$ \\
\hline 1.67 & 2.72 & 8.0 \\
2.50 & 2.102 & 6.673 \\
3.33 & 1.792 & 5.723 \\
4.167 & 1.6 & 5.573 \\
5.0 & 1.454 & 4.923 \\
6.667 & 1.3 & 4.32 \\
8.33 & 1.221 & 3.91 \\
10.0 & 1.006 & 3.507 \\
12.5 & 0.95 & 3.093 \\
14.17 & 0.90 & 2.83 \\
\hline
\end{tabular}

To determine the optimized power for the given combination of bead width, height, and velocity, single weld beads of different cross-sections were modeled on the rectangular substrate. The locations of the weld-bead in the model with some of the bead cross-sections used to create the database are shown in Fig. 3.

The simple simulation model based on a single weld bead was used for estimating the minimum power required to weld each of the different bead's cross-sections with corresponding welding velocity. Different values of welding power were randomly used in simulations until the output temperature of all elements of bead reached the range of $1450-1550{ }^{\circ} \mathrm{C}$ for the steel. The power was then recorded. To estimate the power to weld the beads in a multi-layer geometry, the substrate was preheated to elevated temperatures before welding, i.e., 200 ${ }^{\circ} \mathrm{C}, 400{ }^{\circ} \mathrm{C}, 600{ }^{\circ} \mathrm{C}, 800{ }^{\circ} \mathrm{C}$, and $1000^{\circ} \mathrm{C}$. At higher surface temperature, less power is needed for the WAAM process; hence, the bead size was reduced while the velocity was increased following the relation of velocity and bead size as proposed by Lam et al. [34] In this way, a database containing all essential information of weld-bead cross-section and corresponding power was constructed.

For the one-bead models, more than 100 thermal simulations were conducted using geometry dependent heat source parameters and temperature-dependent convection/radiation coefficients. The results of the simulations were assessed based on an average maximum temperature for every beadelement during welding and a database of the input parameters and temperature output was established.

\subsubsection{Welding of a block geometry}

The available geometric welding parameters of the weld beads, as calculated by Lam et al. [34] were used to build 
Fig. 4 Cross-section of the meshed FE model of the block



the basic simulation model to estimate the optimized power for a specific bead size. Some of the combinations of weld bead width, height and corresponding velocity used to build the basic simulation model are given in Table 3 .

The optimized power for the abovementioned bead sizes was imported from the database and adapted to simulate the welding of the block geometry, taking the different layer temperatures that were reached into account. Welding was performed on a rectangular substrate having a length $\mathrm{L}=121.5$ $\mathrm{mm}$, a width $\mathrm{W}=110 \mathrm{~mm}$, and a height $\mathrm{H}=4 \mathrm{~mm}$. Weld beads and substrate mesh sizes were kept at $2.25 \mathrm{~mm}$ to avoid convergence problems and to ensure sufficient accuracy of the outputs. In simulations for constant power-constant layer height welding, the same element size was used in all layers. The cross-section of the meshed block along with its dimensions is shown in Fig. 4.

Figure 5 illustrates the suggested approach for managing the power and the corresponding bead size in comparison to the constant power WAAM approach that uses a constant power and bead size. In the suggested approach, the heat from previously welded layers is used to weld the bead. By welding the actual bead with a reduced power and smaller cross-section, the heat build-up shall be reduced. The cross-section of the elements in constant power and power controlled approach after each layer is presented in Table 4.

It is important to state here that adapting the power cannot entirely avoid heat accumulation, as the CMT process requires a minimum power to create a stable arc and melt the wire electrode. It is hence necessary, in general, to include idle times between layers. In the conventional constant-power process, the operator can choose between minimizing welding time and accepting a large heat accumulation, thus jeopardizing part quality, or optimizing the process temperature for targets such as maintaining a constant average layer temperature. In the latter case, process time is sacrificed to quality. Between these extremes,
Fig. 5 Schematic illustration of constant power and power controlled WAAM approach for a block
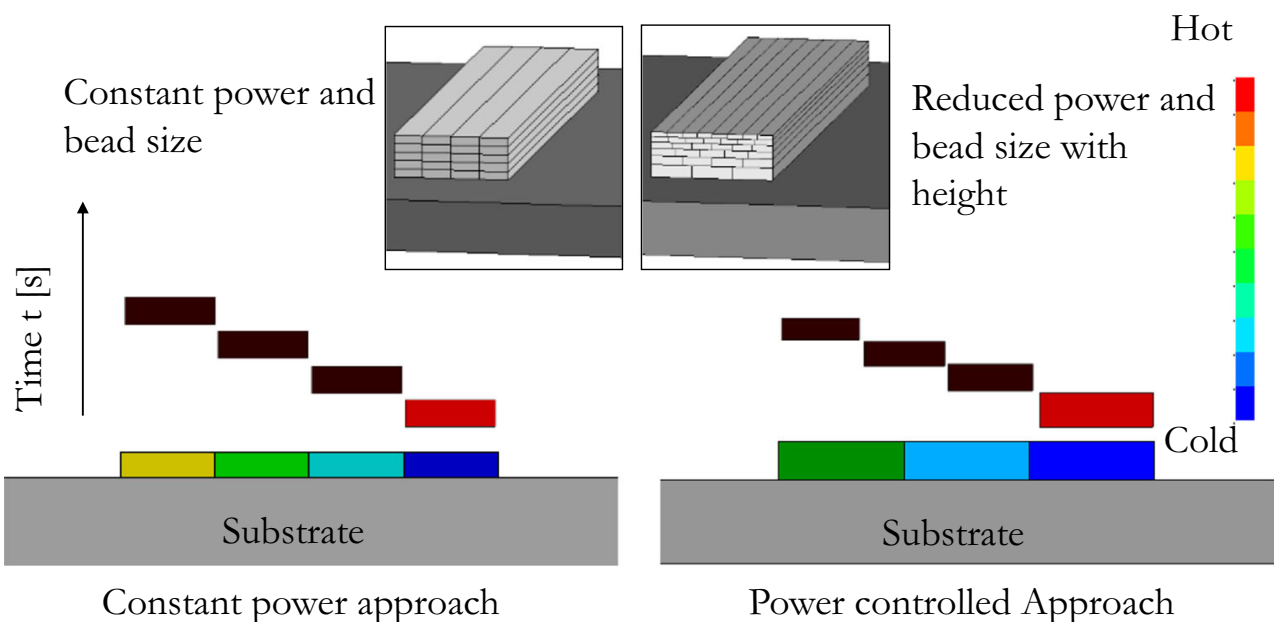

Power controlled Approach 
Table 4 Cross-section of AM elements for different layers in constant power and powercontrolled approach

\begin{tabular}{lll}
\hline $\begin{array}{l}\text { Layer } \\
\text { number }\end{array}$ & $\begin{array}{l}\text { Cross-section of AM elements in constant } \\
\text { power approach } \\
(1 \times \mathrm{w} \times \mathrm{h})\end{array}$ & $\begin{array}{l}\text { Cross-section of AM elements in power } \\
\text { controlled approach } \\
(1 \times \mathrm{w} \times \mathrm{h})\end{array}$ \\
\hline 1 & $2.25 \times 2.25 \times 0.66$ & $2.25 \times 3.0 \times 0.92$ \\
2 & $2.25 \times 2.25 \times 0.66$ & $2.25 \times 2.25 \times 0.66$ \\
3 & $2.25 \times 2.25 \times 0.66$ & $2.25 \times 1.8 \times 0.54$ \\
4 & $2.25 \times 2.25 \times 0.66$ & $2.25 \times 1.5 \times 0.47$ \\
5 & $2.25 \times 2.25 \times 0.66$ & $2.25 \times 1.28 \times 0.40$ \\
\hline
\end{tabular}
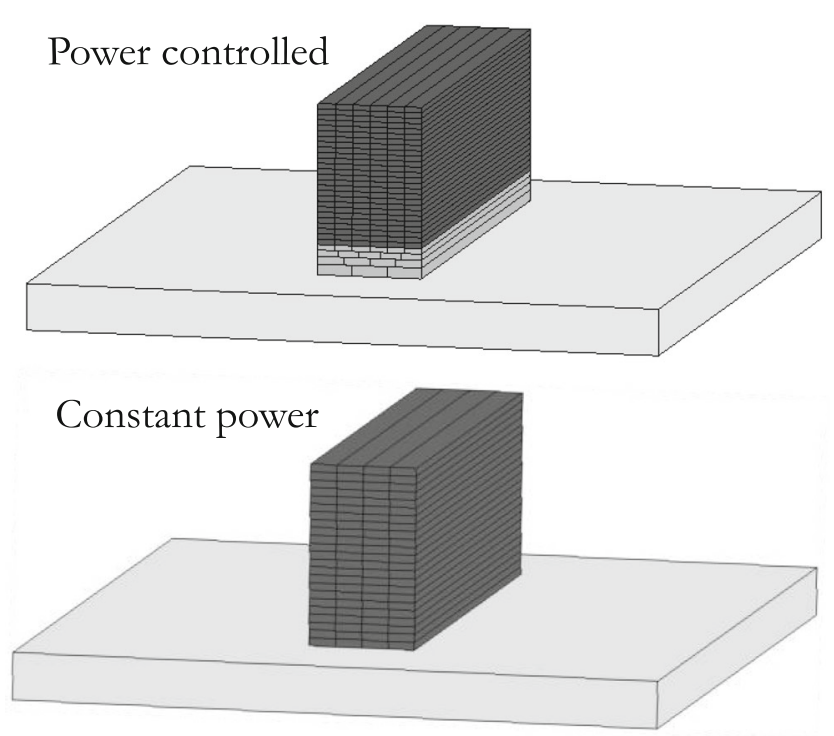

Fig. 6 30-layered block model to control the surface temperature using Pareto principle

various process settings are conceivable as Pareto optimum between welding time and part properties/quality.

Table 5 Estimated welding power for steel 309L (substrate at room temperature) with corresponding values of velocity, bead height, and width from Table 3

\begin{tabular}{llll}
\hline $\begin{array}{l}\text { Welding power P } \\
(\mathrm{kW})\end{array}$ & $\begin{array}{l}\text { Welding velocity } \mathrm{v} \\
(\mathrm{mm} / \mathrm{s})\end{array}$ & $\begin{array}{l}\text { Bead } \\
\text { Height } \mathrm{h} \\
(\mathrm{mm})\end{array}$ & $\begin{array}{l}\text { Bead width } \mathrm{w} \\
(\mathrm{mm})\end{array}$ \\
\hline 1.499 & 1.67 & 2.72 & 8.0 \\
1.399 & 2.50 & 2.102 & 6.673 \\
1.342 & 3.33 & 1.792 & 5.723 \\
1.302 & 4.167 & 1.6 & 5.573 \\
1.281 & 5.0 & 1.454 & 4.923 \\
1.249 & 6.667 & 1.3 & 4.32 \\
1.230 & 8.33 & 1.221 & 3.91 \\
1.199 & 10.0 & 1.006 & 3.507 \\
1.180 & 12.5 & 0.95 & 3.093 \\
1.150 & 14.17 & 0.90 & 2.83 \\
\hline
\end{tabular}

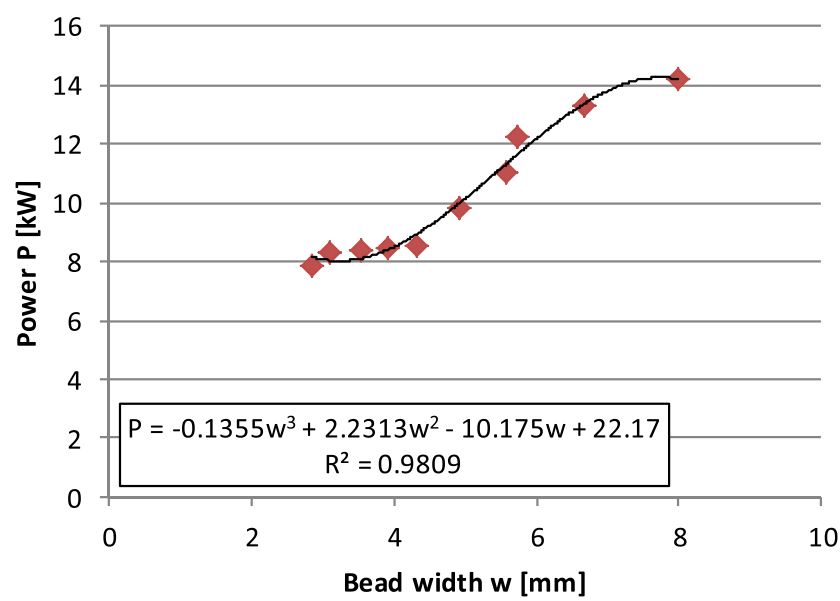

Fig. 7 Scatter chart and interpolation function between welding power and bead width

Adjusting the power should make it possible to shift the Pareto curve in such a way that, e.g., at the same process time, a higher quality, or, at the same target quality, a shorter process time should be feasible.

To investigate the Pareto curves for constant power and power-controlled WAAM, a simulation model of a large block with 30 layers is considered as shown in Fig. 6. The simulations were run with constant-power and with power control, with different pause times between the layers, i.e.,

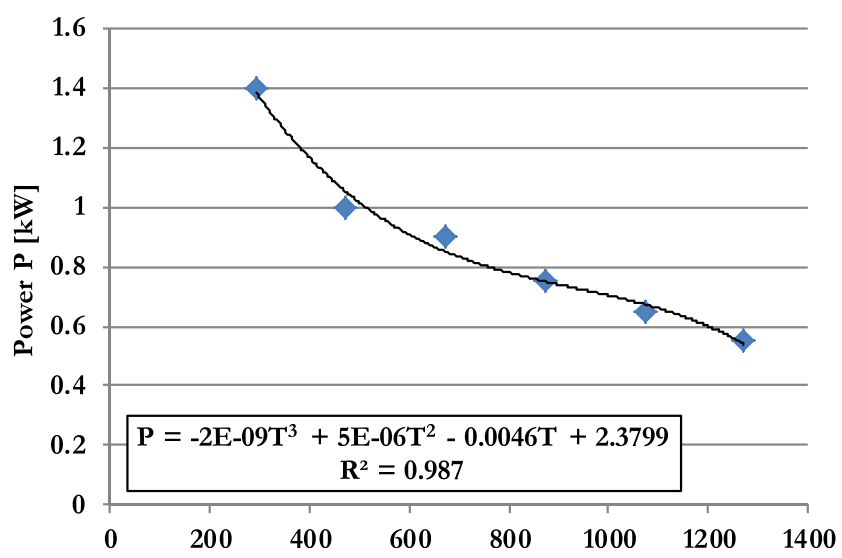

Fig. 8 Interpolation curve for estimating the relation between the power and the initial temperature of the pre-welding surface temperature 
Fig. 9 Optimized powers at various pre-weld surface temperatures for different crosssections of beads based on the established database

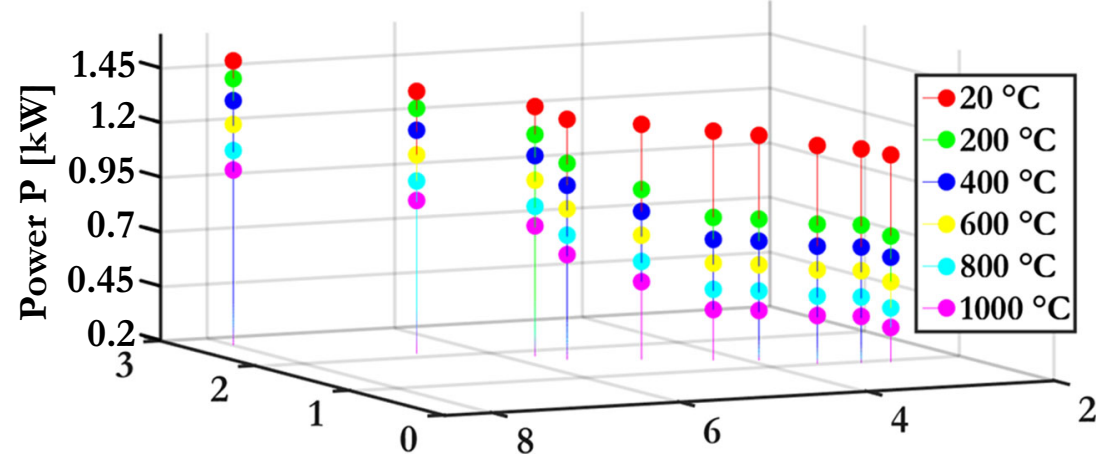

Height of bead h $[\mathrm{mm}]$

Width of bead w [mm]
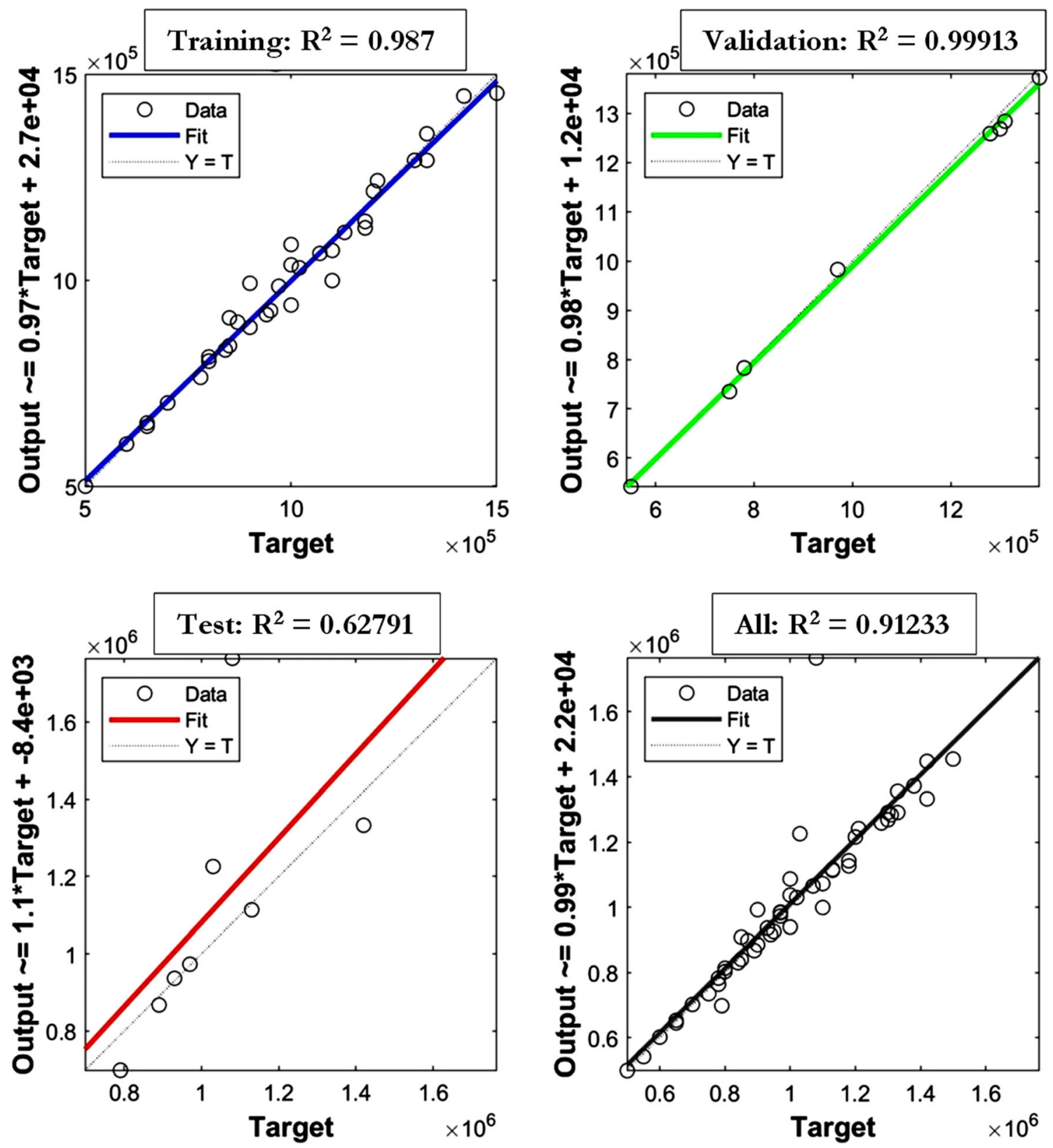

Fig. 10 Surrogate model based on the database showing the regression of the target (power in $\mathrm{mW}$ ) and ANN-output 
Table 6 Input and output parameters for ANN analysis

\begin{tabular}{lll}
\hline ANN analysis & Input parameters & Output parameters \\
\hline & $\begin{array}{ll}\text { Initial temperature } \\
\text { Width of beads }\end{array}$ & Welding power \\
\hline
\end{tabular}

$0 \mathrm{~s}, 5 \mathrm{~s}, 10 \mathrm{~s}$, and $20 \mathrm{~s}$, and the maximum average surface temperature on the layers was retrieved from the simulations.

\section{Results and discussion}

\subsection{Data-driven models of single beads based on simulations}

Table 5 presents the results of the optimized welding power required for welding beads of various cross-sections.

The bead size reduces as the input power decreases. A third degree polynomial could be fitted based on the numerical results, as presented in Fig. 7.

A correlation between the heat source power and the substrate temperature was also established based on the results of FE calculations. If the surface temperature of the substrate increase, less welding power is needed to reach the optimal welding temperature. To model the influence of the substrate temperature, a third order polynomial could be fitted through the simulation results, as shown in Fig. 8.

The 3D-scatter plot (established from the generated database) in Fig. 9 shows the relationship between the optimized powers and the height and width of the beads at different surface temperatures.

$$
\text { Errors }=\text { Targets }- \text { Outputs }
$$

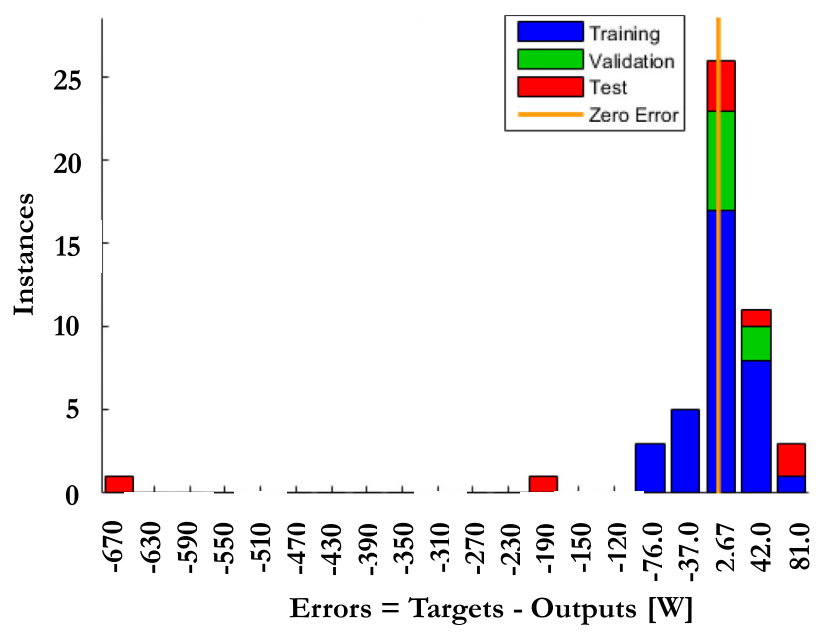

Fig. 11 Error histogram for ANN regression of the welding power
As mentioned before in the state of the art, increasing the height of the model reduces the conduction and enhances heat accumulation. Smaller beads with decreased power are therefore suggested for the upper layers to reduce the energy input.

A data-driven surrogate model was established using an artificial neural network (ANN) with 1 hidden layer of 20 neurons. The ANN is trained by backpropagation learning, for which $70 \%$ of the available data were used as training data and the remaining datasets for validation. The ANN acts as surrogate model that outputs the optimal welding power for different beads and surface temperatures. The surrogate model established on the basis of the database is presented in Fig. 10. The optimized welding power was chosen as output parameter, while the bead width and initial temperature of the substrate were the input parameters (see Table 6).

An overall regression coefficient $\mathrm{R}^{2}=0.91$ was achieved with a flat ANN structure using the data obtained from 100 simulations. Errors in different instances were estimated using equation (6) based on target and output values of power, as shown in Fig. 11. The regression error for half of all simulations amounted to 2.67 Watts.

Errors $=$ Targets-Outputs

\subsection{Simulation of the block geometry}

Two blocks of the same size were simulated using the constant power and power-controlled WAAM to estimate the effectiveness of the proposed power control. The temperature distribution is shown in Fig. 12 at two different instances, i.e., after welding of the second layer and last layer.

The temperature distribution of the block obtained with constant power welding shows a larger region where heat accumulates. This high-temperature region remained confined to the current position of the torch in the powercontrolled process.

The temperature distribution along the cross-section of the model just after welding is shown in Fig. 13.

A larger region with heat accumulation appeared in the constant-power WAAM simulations due to higher total energy input. Not only does the accumulation of heat decrease the cooling rate but it could also cause various defects, such as an inhomogeneous grain structure, thermal stresses, and distortions.

The power-controlled WAAM process resulted in a reduced accumulation of heat. During the entire process, the heated region remained confined to the heat-affected zone close to the welding torch. This not only decreased the power input but also saved process time. The comparison of the temperature history on the blocks simulated by constantpower and power-controlled WAAM at two different points is shown in Fig. 14. 
Fig. 12 Temperature distribution in blocks welded by constant power and power-controlled WAAM after the 2nd layer (a) and welding the complete block (b)

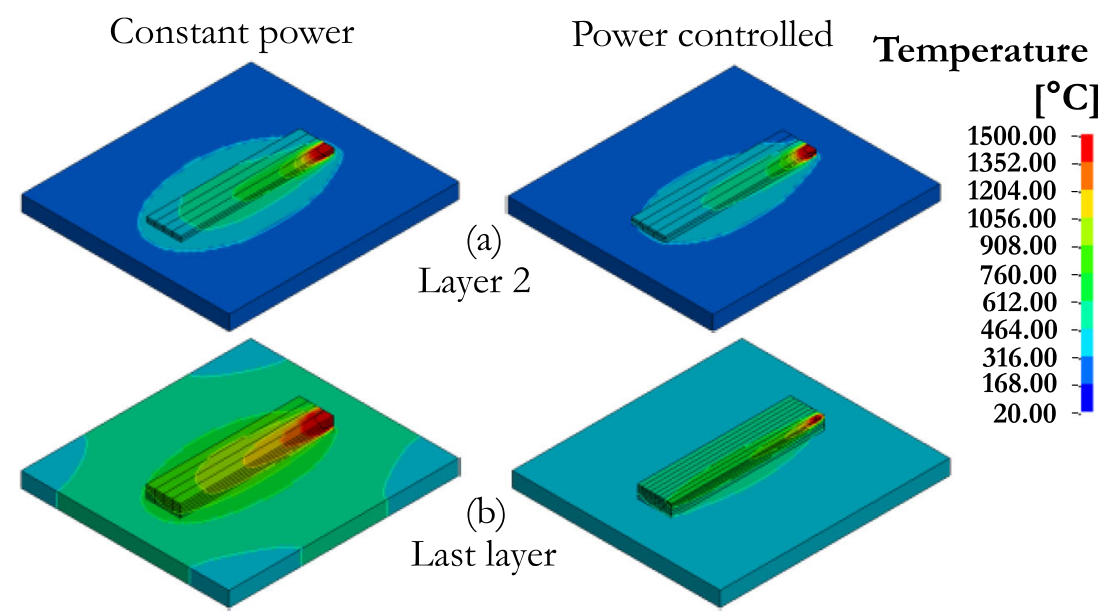

Constant-power WAAM generates higher temperature peaks in each weld bead, resulting in an increase in the model's overall temperature after each layer. In contrast, temperature peaks in the block produced by power-controlled WAAM only showed a maximum when the heat source passed over the reference point. As the number of layers increase, the pre-existing heat is utilized to weld the new beads and the average temperature does not rise considerably.

Therefore, compared to the constant-power process, the block simulated using power-controlled welding accumulated less heat after each layer. The comparison between the total energy input and the total time taken to numerically weld a block of $81 \mathrm{~mm}$ length, $18 \mathrm{~mm}$ width, and $6.7 \mathrm{~mm}$ height with both constant power and power controlled is given in Table 7 .

The proper management of the welding power and bead size reduced the energy input by $27.7 \%$ and saved about $50 \mathrm{~s}$ of process time. Further decreases in welding power and time can be achieved by using even smaller beads in the upper layers. The minimum bead thickness is determined by the

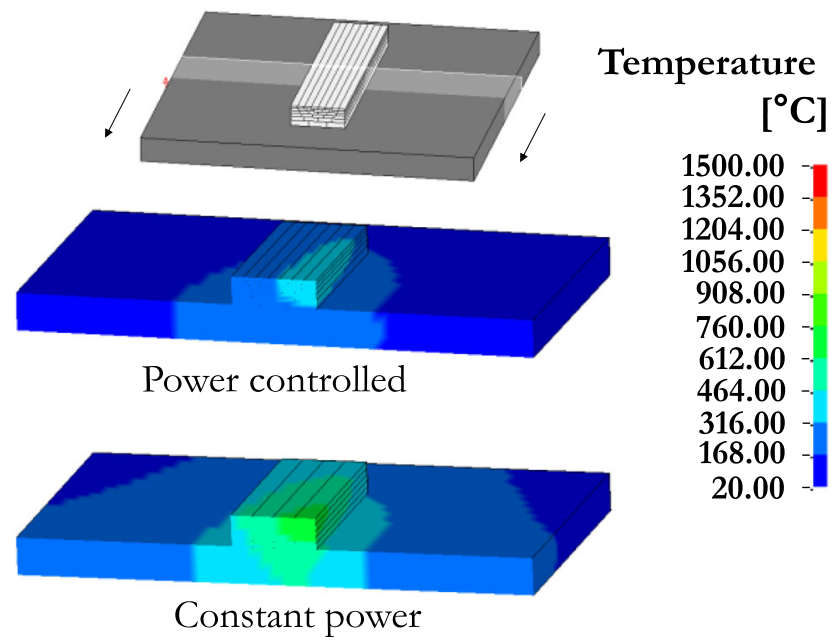

Fig. 13 Cross-section view of temperature distribution on the block and substrate just after welding minimum power required to weld the wire and the largest torch speed at which stable weld beads are formed. Therefore, in this work, only the cases that can be welded in reality were simulated while the other bead sizes were not considered.

\subsection{Experimental validation}

Figs. 15 and 16 show the temperature distributions in the experiments and simulations just after welding each layer of the block using constant power and power controlled WAAM. In the constant power method, after each bead, the constant input energy increased the temperature from layer to layer causing a rise in block temperature.
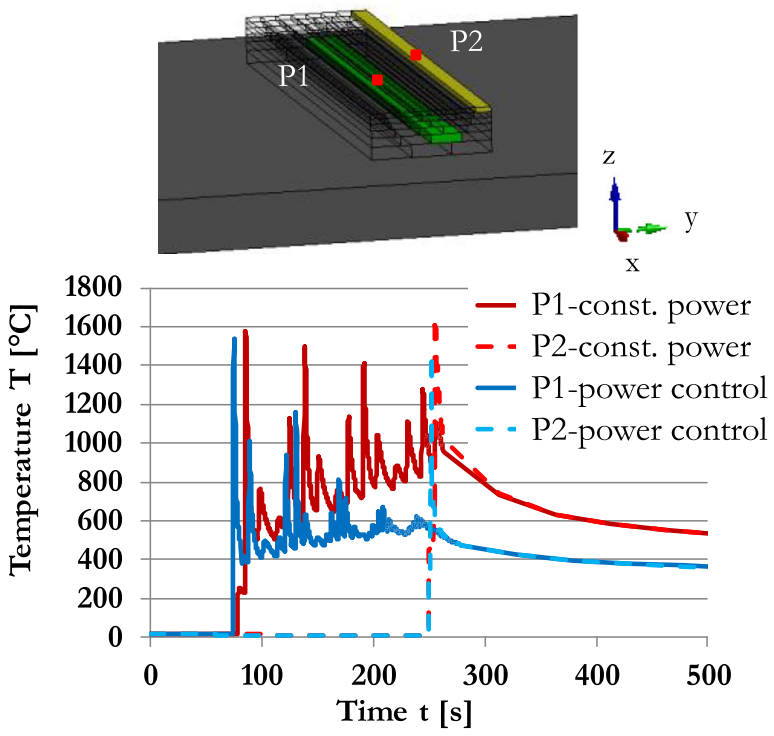

Fig. 14 Temperature history of the FE simulations of a block at two points: P1 (second layer middle) and P2 (last bead middle) welded through the constant power and power controlled WAAM approach 
Table 7 Comparison between the total energy and time required to simulate a block by constant power and power controlled WAAM

\begin{tabular}{lll}
\hline Variable & Constant power approach & Power controlled approach \\
\hline Total thermal energy [Wh] & 2401 & 1736 \\
Total time [s] & 294 & 244 \\
\hline
\end{tabular}

Fig. 15 Comparison of the temperature distribution after every layer of the block welded by constant-power WAAM (simulation vs. experiment)

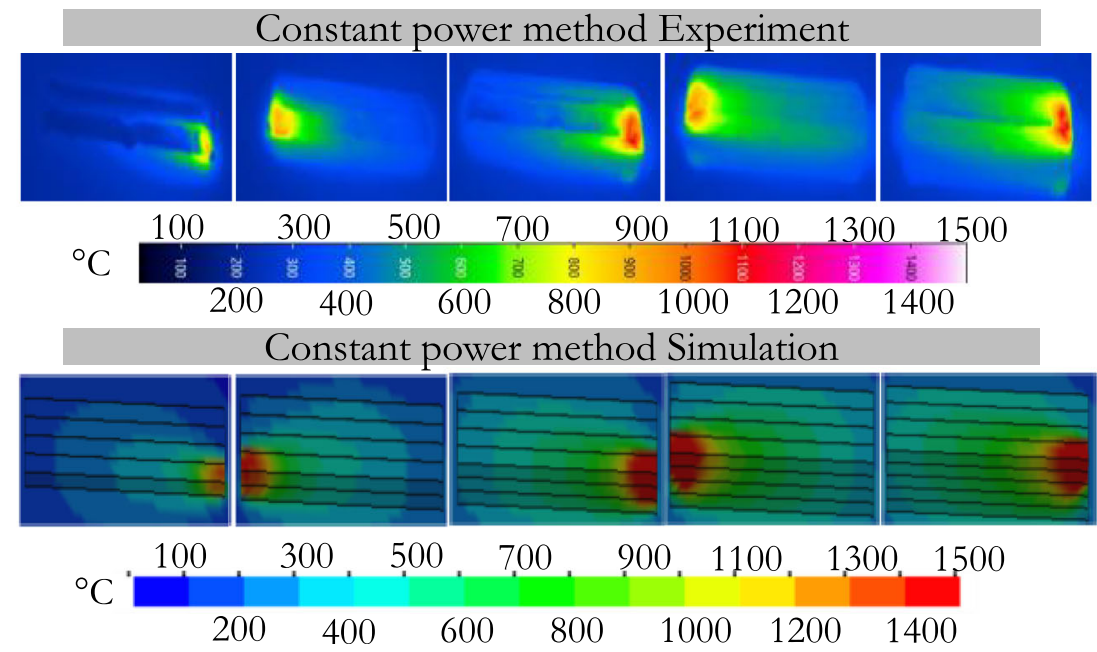

With the power-controlled approach, due to improved power and cross-section control, the region of high temperature remained confined to the zone around the welding torch as shown in Fig. 16.

To validate the numerical results, the thermal histories at different positions of the block were extracted from both the experimental data and the simulation models. The results were compared at three different points in the block (P1-P3) as shown in Fig. 17.

In both simulations and experiments, temperature histories show a similar trend. The power-controlled WAAM process develops lower temperature peaks as compared to the constant power WAAM. The interlayer temperature was also lower in the power-controlled process, which shows the effectiveness of this approach in mitigating heat accumulation and keeping the process time to a minimum.

During welding, less energy was introduced in the power-controlled process, resulting in lower temperature peaks after each welding layer. Microstructure inhomogeneity and areas with large grain sizes caused by high temperatures can therefore be avoided, and mechanical properties can be improved. Two different components
Fig. 16 Comparison of the temperature distribution pattern after every layer of the block welded by power controlled WAAM approach (simulation vs. experiment)

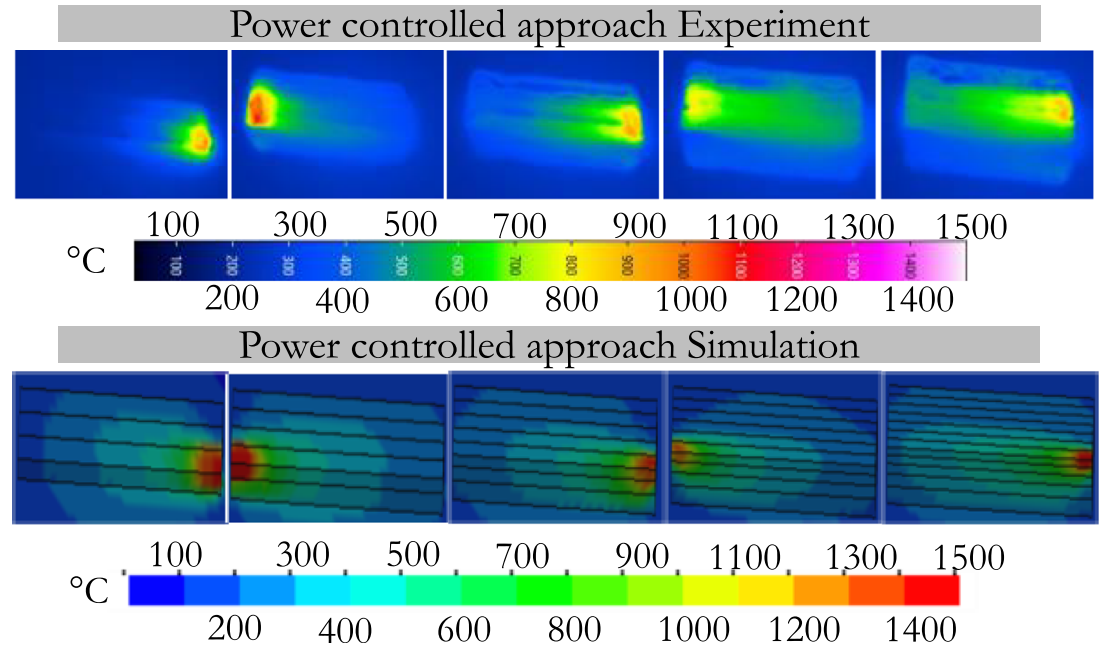




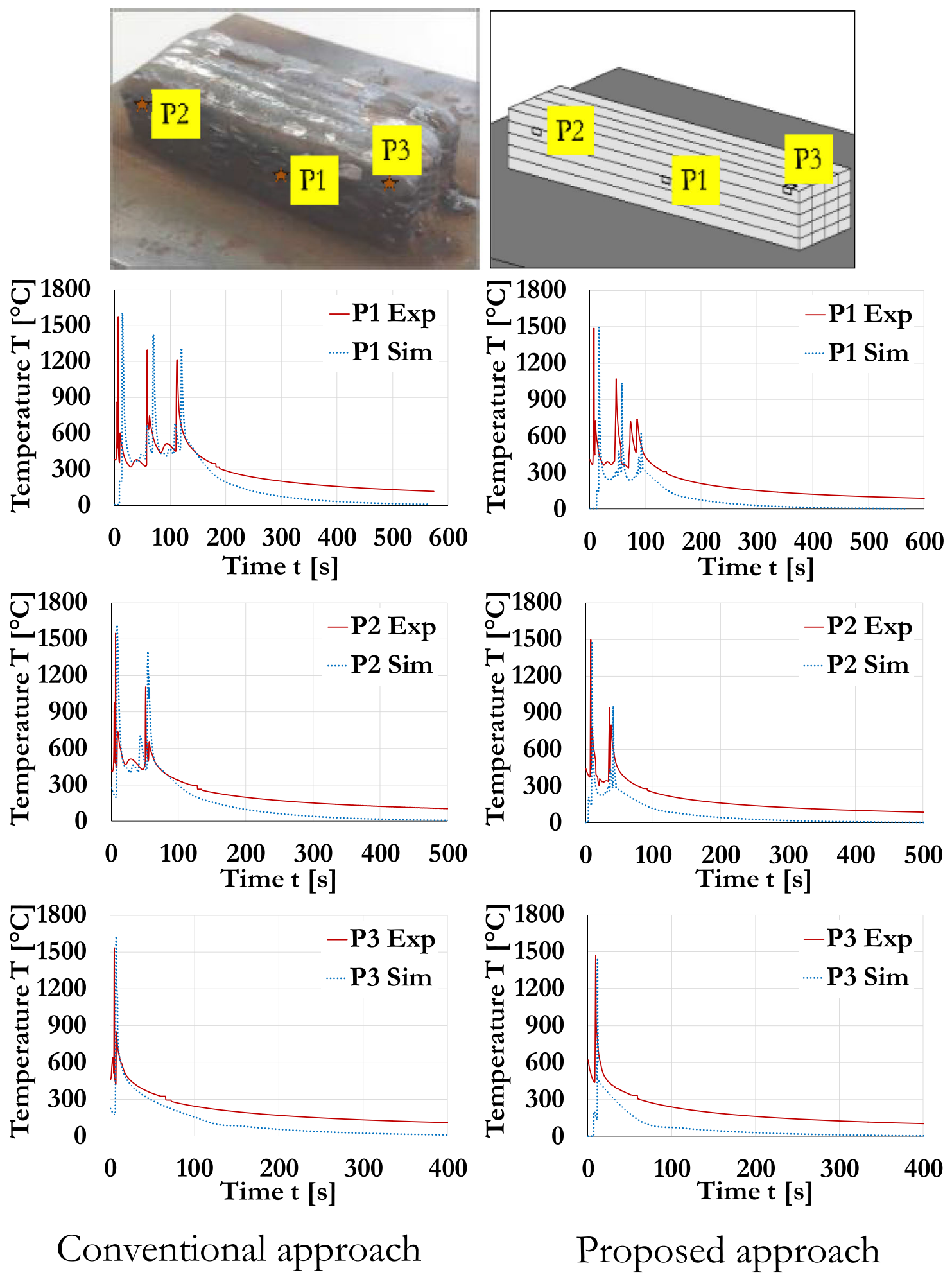

Fig. 17 Thermal history comparison at different points in the experiments and simulations

welded under different operating conditions indicate variations in the microstructure and mechanical properties. Higher temperatures during welding resulted in larger grain sizes (see Fig. 18b) with lower tensile strength and hardness, i.e., $475 \mathrm{~N} / \mathrm{mm}^{2}$ and $135 \mathrm{HV}$, while lower temperatures resulted in smaller grain sizes (see Fig. 18a) with higher tensile strength $470 \mathrm{~N} / \mathrm{mm}^{2}$ and hardness $145 \mathrm{HV}$ respectively. 


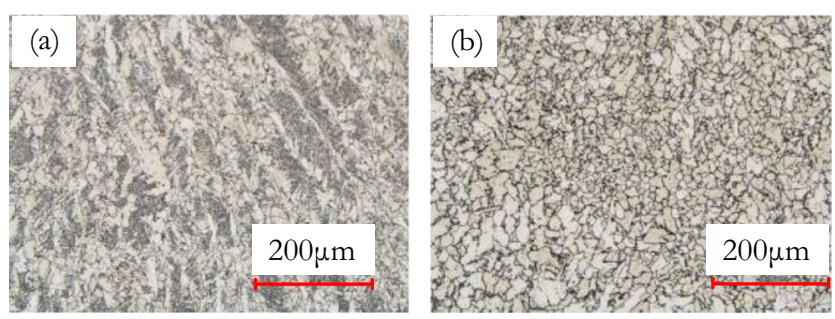

Fig. 18 Microstructure of the material welded at lower temperature (a) and higher temperature (b)

\subsection{Pareto optimal processing}

In this section, the results of the simulation of the large blocks of 30 layers are presented to discuss the Pareto concept for constant-power and power-controlled WAAM.

The simulations were run with different pause times between the layers, i.e., $0 \mathrm{~s}, 5 \mathrm{~s}, 10 \mathrm{~s}$, and $20 \mathrm{~s}$, to retrieve the maximum average surface temperature on the layers before welding the next layer as shown in Fig. 19.

The maximum average layer temperature was computed by averaging the temperature of all elements in the top surface just before welding the next layer, and extracting the maximum value of all layers. In the model with constant power, the maximum layer temperature always occurred before welding the last layer, because of the continuous accumulation of heat. Although the pause times reduce the maximum temperature, the maximum pre-welding temperature always appears in the top layer. In power-controlled process, the maximum layer temperature does not necessarily coincide with the top layer. For example, with $10 \mathrm{~s}$ pause time between the layers, the maximum pre-welding temperature appeared on the 27th layer as shown in Fig. 20.

With an increase in process time, i.e., by adding pauses between the layers, the average maximum temperature on the layers reduces. Compared to constantpower WAAM, power control with pause times shifts the Pareto curve. Thus, the same layer temperature can be obtained at shorter process times or, if process time is kept constant, the layer temperature can be decreased.

In summary, the heat accumulation in WAAM is reduced by controlling the power input without compromising process time too much.

It has to be stated, however, that power-control approach is accompanied by different weld bead cross sections, so that the process design for more intricate geometries needs to handle non-uniform layer thicknesses. The nonuniformity of the thickness in power-controlled WAAM evolves due to different melting rate, which depends on the current, which determines the actual operating point of the power source, i.e., voltage and power. Changing the power thus results in a change of the weld bead shape. Since the weld beads also need an optimal overlap distance, weld beads that are optimal for power input may not be optimal in forming the precise geometry. In order to keep the weld bead shape and hence the layer thickness constant, it would be necessary to find operating points on alternative process characteristics. However, with commercial power sources, this cannot easily be accomplished. Designing process strategies for more complex parts thus needs to rely on advanced path planning.

\section{Conclusions}

The current work introduces and explores the potential of power-controlled WAAM to address the problems of heat accumulation. The following conclusions can be drawn:

- In multi-layered WAAM parts, welding with the same bead cross-section and input power leads to heat accumulation particularly as the distance of the layers from the substrate increases due to the higher pre-welding surface temperature and less heat conduction to the substrate.
Fig. 19 Pareto curves showing the maximum average layer temperature in constant power and power-controlled WAAM as a function of idle time between layers

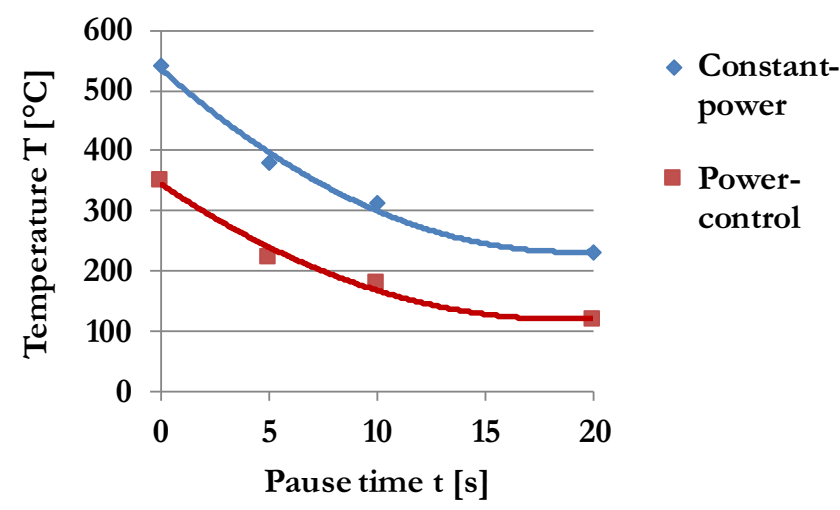




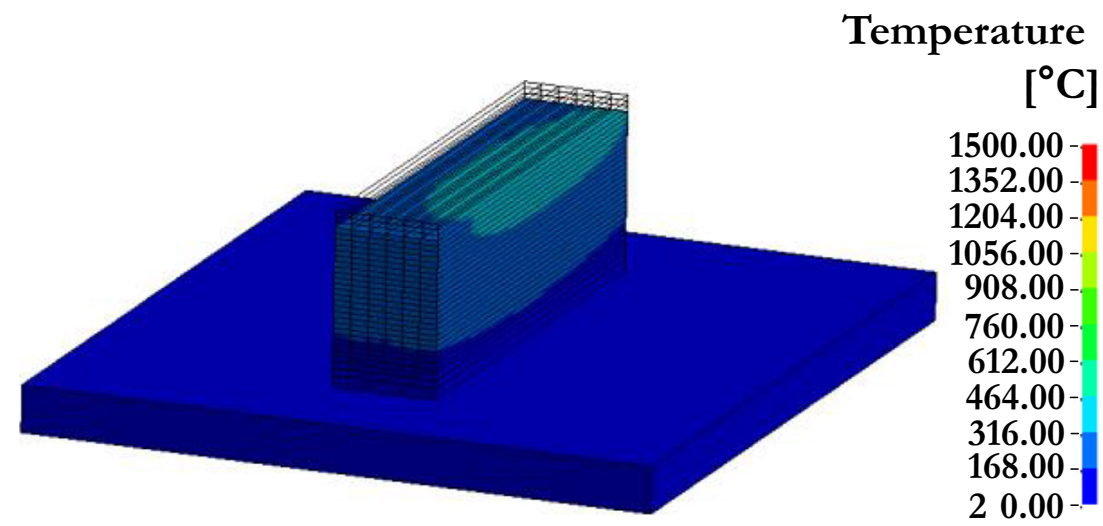

Fig. 20 Maximum average layer temperature with $10 \mathrm{~s}$ pause between each layer occurs in layer 27

- Adjusting the input power in the WAAM process helps reduce the accumulation of heat and allows for shorter inter-layer pause times.

- The relation between average layer-temperature and pause time follows a Pareto curve. Power control can shift this curve so that the same desired layer temperature can be maintained at shorter pause times.

The proposed method has shown promising results in minimizing heat accumulation. In the future, this work will be expanded to set up a database of welding parameters for a wide range of materials and geometries. In addition, path planning with non-uniform weld bead geometries will be tackled.

Acknowledgements Mr. Israr would like to thank the Deutscher Akademischer Austauschdienst e.V. (DAAD) and Higher Education Commission (HEC) of Pakistan for financing this research (DAADHEC-UESTP (50015636)). We would also like to express our gratitude to Mr. Qui Lam Nguyen and Mr. Benjamin Sydow for their support to this work.

Funding Open Access funding enabled and organized by Projekt DEAL. Deutscher Akademischer Austauschdienst e.V. (DAAD) and Higher Education Commission (HEC) of Pakistan for financing this research (DAAD-HEC-UESTP (50015636)).

Data availability If required, the data can be made available for transparency.

Code availability Not applicable

\section{Declarations}

Ethics approval Not applicable

Consent to participate We confirm that the manuscript has been read and approved by all named authors.

Consent for publication The authors agree to publication this article of ACMT conference in the International Journal of Advanced Manufacturing Technology.
Conflict of interest The authors declare that they have no conflict of interest.

Open Access This article is licensed under a Creative Commons Attribution 4.0 International License, which permits use, sharing, adaptation, distribution and reproduction in any medium or format, as long as you give appropriate credit to the original author(s) and the source, provide a link to the Creative Commons licence, and indicate if changes were made. The images or other third party material in this article are included in the article's Creative Commons licence, unless indicated otherwise in a credit line to the material. If material is not included in the article's Creative Commons licence and your intended use is not permitted by statutory regulation or exceeds the permitted use, you will need to obtain permission directly from the copyright holder. To view a copy of this licence, visit http://creativecommons.org/licenses/by/4.0/.

\section{References}

1. Bambach M, Sizova I. Hot working behavior of selective laser melted and laser metal deposited Inconel 718. https://doi.org/10. $1063 / 1.5035058$.

2. Haden CV, Zeng G, Carter FM, Ruhl C, Krick BA, Harlow DG (2017) Wire and arc additive manufactured steel: Tensile and wear properties. Addit Manuf 16:115-123. https://doi.org/10.1016/j. addma.2017.05.010

3. Williams SW, Martina F, Addison AC, Ding J, Pardal G, Colegrove $\mathrm{P}$ (2015) Wire + arc additive manufacturing. Mater Sci Technol 32(7):641-647. https://doi.org/10.1179/1743284715Y. 0000000073

4. Ding D, Pan Z, Cuiuri D, Li H (2015) Wire-feed additive manufacturing of metal components: technologies, developments and future interests. Int J Adv Manuf Technol 81(1-4):465-481. https://doi.org/10.1007/s00170-015-7077-3

5. Bambach M, Sizova I, Emdadi A (2019) Development of a processing route for Ti-6Al-4V forgings based on preforms made by selective laser melting. J Manuf Process 37:150-158. https://doi. org/10.1016/j.jmapro.2018.11.011

6. Ding J (2012) Thermo-mechanical analysis of wire and arc additive manufacturing process [ $\mathrm{PhD}$ thesis]

7. He T, Yu S, Shi Y, Huang A (2020) Forming and mechanical properties of wire arc additive manufacture for marine propeller bracket. J Manuf Process 52:96-105. https://doi.org/10.1016/j. jmapro.2020.01.053

8. Laghi V, Palermo M, Gasparini G, Trombetti T (2020) Computational design and manufacturing of a half-scaled 3D- 
printed stainless steel diagrid column. Addit Manuf 36:101505. https://doi.org/10.1016/j.addma.2020.101505

9. Honnige J, Williams S, Roy M, Colegrove P, Ganguly S Residual stress characterization and control in the additive manufacture of large scale metal structures. https://doi.org/10.21741/ 9781945291173-77

10. Gardner L, Kyvelou P, Herbert G, Buchanan C (2020) Testing and initial verification of the world's first metal 3D printed bridge. J Constr Steel Res 172:106233. https://doi.org/10.1016/j.jcsr.2020.106233

11. Xiong J, Lei Y, Li R (2017) Finite element analysis and experimental validation of thermal behavior for thin-walled parts in GMAWbased additive manufacturing with various substrate preheating temperatures. Appl Therm Eng 126:43-52. https://doi.org/10. 1016/j.applthermaleng.2017.07.168

12. Wen S, Dong H, Zhang SY, Bannister A, Connelly M. Neutron diffraction measurement of weld residual stresses in an UOE linepipe subjected to mechanical expansion. https://doi.org/10. 1115/OMAE2013-11257.

13. Klingbeil N, Beuth J, Chin R, Amon C (2002) Residual stress-induced warping in direct metal solid freeform fabrication. Int J Mech Sci 44(1): 57-77. https://doi.org/10.1016/S0020-7403(01)00084-4

14. Yang D, Wang G, Zhang G (2017) Thermal analysis for single-pass multi-layer GMAW based additive manufacturing using infrared thermography. J Mater Process Technol 244:215-224. https://doi. org/10.1016/j.jmatprotec.2017.01.024

15. Wu B, Pan Z, Ding D, Cuiuri D, Li H, Fei Z (2018) The effects of forced interpass cooling on the material properties of wire arc additively manufactured Ti6Al4V alloy. J Mater Process Technol 258:97-105. https://doi.org/10.1016/j.jmatprotec.2018.03.024

16. Xiong J, Lei Y, Chen H, Zhang G (2017) Fabrication of inclined thinwalled parts in multi-layer single-pass GMAW-based additive manufacturing with flat position deposition. J Mater Process Technol 240:397-403. https://doi.org/10.1016/j.jmatprotec.2016.10.019

17. Wu B, Ding D, Pan Z, Cuiuri D, Li H, Han J et al (2017) Effects of heat accumulation on the arc characteristics and metal transfer behavior in wire arc additive manufacturing of Ti6Al4V. J Mater Process Technol 250:304-312. https://doi.org/10.1016/j. jmatprotec.2017.07.037

18. Manvatkar V, De A, DebRoy T (2014) Heat transfer and material flow during laser assisted multi-layer additive manufacturing. J Appl Phys 116(12):124905. https://doi.org/10.1063/1.4896751

19. Hoshi A, Mills DR, Bittar A, Saitoh TS (2005) Screening of high melting point phase change materials (PCM) in solar thermal concentrating technology based on CLFR. Sol Energy 79(3):332-339. https://doi.org/10.1016/j.solener.2004.04.023

20. Li LC, Chai MY, Li YQ, Bai WJ, Duan Q (2013) Effect of welding heat input on grain size and microstructure of $316 \mathrm{~L}$ stainless steel welded joint. AMM 331:578-582. https://doi.org/10.4028/www. scientific.net/AMM.331.578

21. Chen X, Qiao G, Han X, Wang X, Xiao F, Liao B (2014) Effects of $\mathrm{Mo}, \mathrm{Cr}$ and $\mathrm{Nb}$ on microstructure and mechanical properties of heat affected zone for Nb-bearing X80 pipeline steels. Mater Des 53: 888-901. https://doi.org/10.1016/j.matdes.2013.07.037

22. Pandey C, Mahapatra MM (2016) Effect of groove design and postweld heat treatment on microstructure and mechanical properties of P91 steel weld. J Mater Eng Perform 25(7):2761-2775. https://doi. org/10.1007/s11665-016-2127-Z

23. Wu B, Pan Z, Ding D, Cuiuri D, Li H (2018) Effects of heat accumulation on microstructure and mechanical properties of Ti6Al4V alloy deposited by wire arc additive manufacturing. Addit Manuf 23:151-160. https://doi.org/10.1016/j.addma.2018.08.004

24. Rajamanickam N, Balusamy V, Madhusudhanna Reddy G, Natarajan K (2009) Effect of process parameters on thermal history and mechanical properties of friction stir welds. Mater Des 30(7): 2726-2731. https://doi.org/10.1016/j.matdes.2008.09.035

25. Eagar TW, Tsai NS Temperature fields produced by traveling distributed heat sources. Weld Res Suppl (United States)

26. Barsoum Z, Lundbäck A (2009) Simplified FE welding simulation of fillet welds $-3 D$ effects on the formation residual stresses. Eng Fail Anal 16(7):2281-2289. https://doi.org/10.1016/j.engfailanal. 2009.03.018

27. Lindgren L-E, Häggblad H-A, McDill J, Oddy AS (1997) Automatic remeshing for three-dimensional finite element simulation of welding. Comput Methods Appl Mech Eng 147(3-4):401409. https://doi.org/10.1016/S0045-7825(97)00025-X

28. Teng T-L, Chang P-H, Tseng W-C (2003) Effect of welding sequences on residual stresses. Comput Struct 81(5):273-286. https:// doi.org/10.1016/S0045-7949(02)00447-9

29. Mackerle J (1996) Finite element analysis and simulation of welding: a bibliography (1976 - 1996). Model Simul Mater Sci Eng 4(5):501-533. https://doi.org/10.1088/0965-0393/4/5/006

30. Kozamernik N, Bračun D, Klobčar D (2020) WAAM system with interpass temperature control and forced cooling for near-net-shape printing of small metal components. Int $\mathrm{J}$ Adv Manuf Technol 110(7-8):1955-1968. https://doi.org/10.1007/s00170-020-05958-8

31. Derekar K, Lawrence J, Melton G, Addison A, Zhang X, Xu L et al (2019) Influence of interpass temperature on wire arc additive manufacturing (WAAM) of aluminium alloy components. MATEC Web Conf 269(7):5001. https://doi.org/10.1051/ matecconf/201926905001

32. Silva RHG, Rocha PCJ, Rodrigues MB, Pereira M, Galeazzi D (2020) Analysis of interlayer idle time as a temperature control technique in additive manufacturing of thick walls by means of CMT and CMT pulse welding processes. Soldag Insp 25(2):589. https://doi.org/10.1590/0104-9224/SI25.01

33. Hu Z, Qin X, Shao T (2017) Welding thermal simulation and metallurgical characteristics analysis in WAAM for $5 \mathrm{CrNiMo}$ hot forging die remanufacturing. Procedia Eng 207:2203-2208. https://doi. org/10.1016/j.proeng.2017.10.982

34. Lam Nguyena, Johannes Buhl, Katharina Eissing, Markus Bambach (2020) Wire-arc additive manufacturing of curved thin-walled hollow structures by control of welding speed and distortion compensation using virtual bending moments (Submitted under review)

35. Goldak J, Chakravarti A, Bibby M (1984) A new finite element model for welding heat sources. MTB 15(2):299-305. https://doi. org/10.1007/BF02667333

36. Israr R, Buhl J, Elze L, Bambach M (2018) Simulation of different path strategies for wire-arc additive manufacturing with Lagrangian finite element methods 15. LS-DYNA Forum 2018, Bamberg.

37. Bhusan Prasad B (2018) Simulation of heat source in gas metal arc welding by using LS-PrePost (Tutorial), pp 1-32

38. Winczek J, Mičian M, Ivanov V (2018) The modelling of temperature-dependent stress-strain curves for weldable steels. J Appl Math Comput Mech 17(3):111-117. https://doi.org/10. 17512/jamcm.2018.3.10

39. Kowalski M, Böhm M Numerical simulation of residual stress induced by welding of steel-aluminum transition joint, pp 346-352. https://doi.org/10.1007/978-3-030-04975-1_40

40. Miłkowska-Piszczek K, Rywotycki M, Falkus J, Konopka K (2015) A comparison of models describing heat transfer in the primary cooling zone of a continuous casting machine. Arch Metall Mater 60(1):239-244. https://doi.org/10.1515/amm-20150038

Publisher's note Springer Nature remains neutral with regard to jurisdictional claims in published maps and institutional affiliations. 